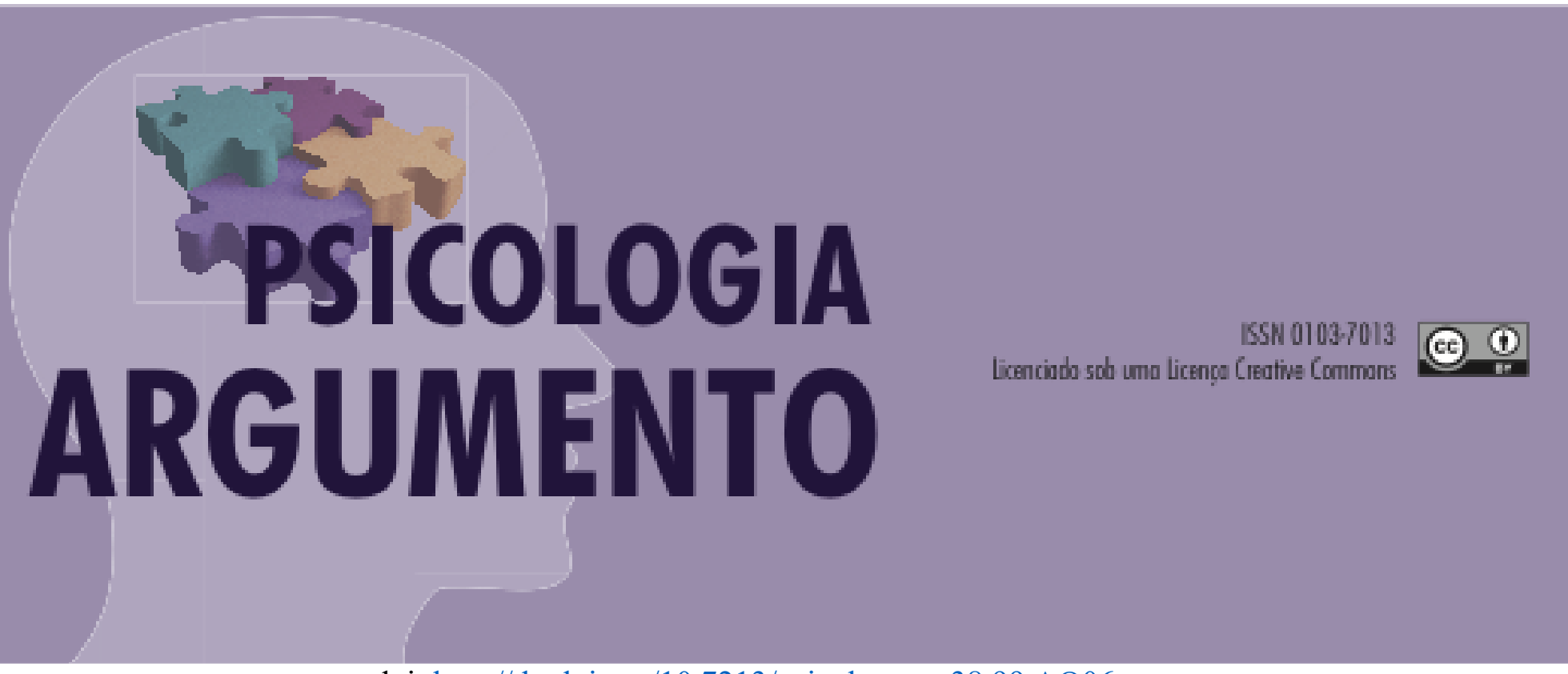

doi: http://dx.doi.org/10.7213/psicolargum.38.99.AO06

\title{
A representação científica do comportamento: Merleau-Ponty e a crítica à fisiologia clássica.
}

The scientific representation of behavior: Merleau-ponty and the critique of the classical physiology

La representación científica del comportamiento: Merleau-Ponty y la crítica de la fisiologia clássica.

Pedro Henrique Santos Decanini Marangoni

Doutorando em Psicologia - Universidade Estadual Paulista (UNESP). Email:

pedro.marangoni@yahoo.com.br.https://orcid.org/0000-0002-2473-4514

Danilo Saretta Verissimo

Docente do Departamento de Psicologia Social e Educacional e do PPG em Psicologia -

Universidade Estadual Paulista (UNESP). Email: danilo.verissimo@gmail.com

https://orcid.org/0000-0002-7981-3877

\begin{abstract}
Resumo
No presente artigo, analisamos a gênese e a extensão das críticas realizadas por Merleau-Ponty, em sua obra A Estrutura do Comportamento, à fisiologia clássica, representada pela teoria do reflexo de Ivan Pavlov. Merleau-Ponty se apropria da fisiologia contemporânea, especialmente do pensamento de Kurt Goldstein, para questionar a centralidade teórica e experimental ocupada pela noção de reflexo nos estudos experimentais sobre o comportamento. Trata-se de investigar os limites da teoria reflexológica, expondo a insuficiência do método como explicação objetiva do comportamento. Pretendemos explicitar que a interlocução com o campo da físiologia não sinaliza, nesta obra, uma atitude de afastamento dos problemas filosóficos, mas expressa o movimento necessário de revisão epistemológica e metodológica tanto das ciências naturais, como da própria filosofia.
\end{abstract}

Palavras-chave: Merleau-Ponty, Goldstein, Pavlov, comportamento, reflexo. 


\begin{abstract}
In this article, we analyze the genesis and extent of the criticisms made by Merleau-Ponty, in his work The Structure of Behavior, to classical physiology, represented by Ivan Pavlov's reflex theory. Merleau-Ponty appropriates contemporary physiology, especially Kurt Goldstein's thought, to question the theoretical and experimental centrality occupied by the notion of reflex in experimental behavioral studies. It is a case of investigating the limits of the reflexological theory, in order to expose the insufficiency of the method as an objective explanation of the behavior. We explicit that the interlocution with the field of physiology does not signal in this work to a distant attitude from philosophical problems, but it expresses the necessary movement of epistemological and methodological revision of both the natural sciences and philosophy itself.
\end{abstract}

Keywords: Merleau-Ponty, Goldstein, Pavlov, behavior, reflex

\title{
Resumen
}

Este artículo analiza la génesis y el alcance de las críticas hechas por Merleau-Ponty en su trabajo, La structura del comportamiento, a la fisiología clásica, representada por la teoría del reflejo de Ivan Pavlov. Merleau-Ponty se apropia de la fisiología contemporánea, especialmente del pensamiento de Kurt Goldstein, para cuestionar la centralidad teórica y experimental ocupada por la noción de reflejo en los estudios experimentales de comportamiento. Se trata de investigar los límites de la teoría reflexológica, exponiendo la insuficiencia del método como una explicación objetiva del comportamiento. Pretendemos explicar que la interlocución con el campo de la fisiología no indica, en este trabajo, una actitud de distanciamiento de los problemas filosóficos, sino que expresa el movimiento necesario de revisión epistemológica y metodológica tanto de las ciencias naturales como de la filosofía misma.

Palabras clave: Merleau-Ponty, Goldstein, Pavlov, comportamiento, reflejo

\section{Introdução}

Em seu pedido de renovação da subvenção concedida pela Caixa Nacional de Ciências da França em 1934, intitulado A natureza da percepção, Merleau-ponty (1971/1989) elenca algumas contribuições científicas e filosóficas de seu tempo que justificariam o retorno ao clássico problema da percepção. Dentre os motivos que legitimariam novos estudos em torno do fenômeno perceptivo o filósofo destaca o desenvolvimento de pesquisas no campo da psicopatologia e da fisiologia do sistema nervoso. Embora Merleau-Ponty evoque a fisiologia de modo maciço, tanto para criticá-la como para dela servir-se, sua intenção primordial é dispor da noção de comportamento como estratégia para reexaminar as relações entre consciência e natureza.

O objetivo da primeira obra de Merleau-Ponty, A Estrutura do comportamento, é “compreender as relações entre a consciência e a natureza - orgânica, psicológica ou mesmo social" (1942/1967, p. 1). Para tanto, Merleau-Ponty lança mão de uma estratégia metodológica não convencional para o cenário filosófico de sua época. Ao invés de se ater 
a uma explicação subjetiva da consciência, segundo a qual a conduta seria descrita a partir do ponto de vista do sujeito que a vive, o autor opta por instalar-se no discurso científico da Psicologia e da Fisiologia do final do século XIX e início do século XX, caracterizado, principalmente, pela afirmação do primado da exterioridade sobre a interioridade. A noção de "comportamento" adquire um valor central neste contexto: Merleau-Ponty a transforma em diretriz conceitual que o permite reavaliar os desdobramentos do dualismo entre mente e corpo, tais como a cisão entre psíquico e físico e interioridade e exterioridade (Geraets, 1972). Este método do "espectador estrangeiro" (Merleau-Ponty, 1942/1967, p.175) confere à Merleau-Ponty a flexibilidade de se amparar nos resultados experimentais e nas novas articulações teóricas da psicologia, psicopatologia e da fisiologia de sua época para confrontar a herança atomista dos estudos do comportamento. Tais novidades, representadas especialmente nas figuras da Psicologia da Gestalt e da biologia de Kurt Goldstein, fornecem o essencial para uma crítica que se dirige ao ao núcleo conceitual das perspectivas atomistas e mecanicistas do comportamento: o reflexo. Este contexto de vinculação da psicologia com as ciências naturais, e sua aproximação específica com a fisiologia, tem claras consequências metodológicas e epistemológicas na produção de conhecimento acerca do comportamento. O emprego de métodos quantitativos e análises parciais, que decompõem os dados comportamentais em correlatos anatômicos e fisiológicos, respondem a um determinado fundo filosófico, comprometido com o atomismo e o determinismo, do qual emerge a conceituação do comportamento como resultado de processos fisiológicos elementares (Merleau-Ponty, 1942/1967). De acordo com Barbaras (2001, p.153), no contexto d'A Estrutura do Comportamento, “ MerleauPonty se opõe principalmente à reflexologia de Pavlov, que consiste em reconstruir o comportamento de maneira longitudinal como uma reação característica a um estímulo objetivo específico, segundo uma via nervosa definida". Todo o esquema do comportamento resumir-se-ia a um "circuito reflexo". O estímulo considerado como entidade física é conduzido por vias nervosas pré-estabelecidas que acionariam áreas determinadas do córtex cerebral, as quais, por sua vez, determinariam reações específicas. As propriedades físico-químicas do estímulo correlacionar-se-iam com setores sensoriais previamente preparados, pressupondo-se uma linearidade na recepção das informações. A percepção seria reduzida ao contato imediato com o estímulo, acolhido pelas vias sensoriais e posteriormente processado de acordo com o jogo de excitações e inibições que influenciam o patamar nervoso da resposta. Todo este esquema, que pode ser expresso sob 
o conceito de 'reflexo', é o cenário geral das discussões de Merleau-Ponty com a fisiologia clássica.

Defendemos a hipótese de que em toda análise desenvolvida por Merleau-Ponty (1942/1967) acerca da concepção científica de comportamento, predomina a crítica a dois princípios do conhecimento fisiológico que determinam todo o edifício da concepção clássica de reflexo. Primeiro, a ideia de que os estímulos exteroceptivos, vindos do exterior, são a causa do comportamento e, em segundo lugar, a concepção segundo a qual as funções psicológicas estão estritamente localizadas em áreas específicas do substrato nervoso. Nossas reflexões desenvolver-se-ão como uma explicitação da crítica de Merleau-Ponty a estes dois pontos.

É oportuno destacar que a crítica filosófica relega A Estrutura do Comportamento a um lugar secundário no pensamento do filósofo francês, se comparada a textos posteriores, como a Fenomenologia da Percepção e o Visível e o Invisível. De maneira similar, a literatura psicológica e neurocientífica, até recentemente, negligenciou as contribuições do filósofo francês para estas áreas (Ellis, 2006). Considerada por alguns autores como uma obra "subestimada" (Thompson, 2007; Smith, 2007), A Estrutura do Comportamento tem recebido gradual atenção, especialmente a partir dos anos 90, por parte de pesquisas no campo das ciências cognitivas e das neurociências, como é o caso do livro escrito por Varela, Thompson e Rosch, intitulado The Embodied Mind: Cognitive sciences and human experience, em que os autores se reportam de modo recorrente à filosofia inicial de Merleau-Ponty. À primeira vista, este movimento de retorno às primeiras obras do autor francês tem como prerrogativa fornecer modelos de explicação da cognição que não se valham da noção de representação e que compreendam a cognição como um fenômeno essencialmente sensório-motor. Não é nossa intenção examinar em detalhes a gênese do pensamento inicial de Merleau-Ponty no atual desenvolvimento das ciências cognitivas, o que demandaria um artigo à parte. No entanto, tendo em vista a importância d'A Estrutura do Comportamento no campo das ciências cognitivas e das neurociências, nossa proposta consiste em clarificar os fundamentos críticos e propositivos que embasam a superação do paradigma reflexológico como método de investigação dos fenômenos nervosos. Este estudo justifica-se de duas maneiras. Em primeiro lugar, ao propor-nos explicitar o movimento argumentativo de Merleau-Ponty no campo das discussões sobre a fisiologia do comportamento e do cérebro, temos o propósito de trazer à luz um debate que pode auxiliar a entender a apropriação recente 
das ideias do autor, sinalizada anteriormente. $\mathrm{O}$ exame proposto justifica-se ainda pelo número incipiente de publicações, na literatura científica brasileira, que se empenham em aclarar as discussões de Merleau-Ponty com a fisiologia e com a psicologia científica.

De início, centramo-nos nas discussões acerca da caracterização clássica do circuito reflexo com o propósito de enfatizar que os contrapontos desenvolvidos por Merleau-Ponty situam-se em uma perspectiva orientada pelos trabalhos de Kurt Goldstein. Em seguida, discutimos o papel desempenhado pelas intervenções cerebrais na atividade reflexa e a concepção localizacionista de função psicológica, expondo em detalhes a proposta de interpretação fundada na ideia de um funcionamento gestáltico do sistema nervoso em oposição à caracterização atomista da atividade nervosa. Ao final, apresentamos a ideia de que o cerne da crítica à noção de reflexo está vinculado à reformulação da noção de organismo, o que nos conduz a delimitar ainda mais a influência de Kurt Goldstein na primeira obra de Merleau-Ponty.

\section{Método}

A respeito da estrutura metodológica adotada, este estudo situa-se em uma perspectiva de análise exegética da obra de Merleau-Ponty, o que implica, principalmente, o mapeamento e a exposição do modo como o autor integrou à reflexão filosófica os resultados experimentais da fisiologia de sua época, encarnada, sobretudo, na figura de Kurt Goldstein, para tecer a crítica à concepção mecanicista de comportamento, representada na figura de Pavlov. O desenvolvimento de nossa análise conceitual inspira-se nos parâmetros propostos por Laurenti (2016). A autora concebe quatro abordagens metodológicas principais para a pesquisa teórica em Psicologia e Filosofia. Em um primeiro nível, considerado mais elementar, busca-se a identificação e análise dos principais conceitos de uma dada teoria psicológica ou filosófica. O segundo nível de análise conceitual proposto pela autora é a análise sistêmica, a qual consiste em explicitar a rede relacional de um conceito, isto é, sua conexão direta ou indireta com outras ideias que a fundamentam. A terceira abordagem é a análise de contraste. Nesta proposta, interpelam-se os conceitos da psicologia com conceitos da filosofia, a fim de compreender as ressonâncias e interpretações presentes nas dimensões epistemológica, ética, política e metafísica. Por fim, a última categoria discutida pela autora concerne à análise histórica, a qual procura situar os conceitos e o próprio texto em seu tempo histórico, dialogando com o espírito da época. De acordo com a autora, tais dimensões da 
pesquisa estão intrinsecamente relacionadas (Laurenti, 2016). Porém, é possível que cada qual receba uma ênfase diferente a depender dos objetivos do trabalho. Em nossa pesquisa, a ênfase recai em dois pontos principais: a) explicitar o conceito de reflexo no estudo do comportamento e b) clarificar a crítica de Merleau-Ponty à reflexologia, indicando os pontos em que atua o pensamento de Kurt Goldstein. A partir da identificação de um conceito-chave, o reflexo, desenvolve-se uma reflexão pautada no contraste da fisiologia de Pavlov com a teoria de Goldstein. Situamo-nos, portanto, principalmente no primeiro e no terceiro níveis de análise conceitual, embora o método de contraste esteja prenhe de motivos históricos.

\section{Discussão}

Fisiologia clássica e teoria do circuito reflexo.

A noção de reflexo simples é definida por Pavlov (1909/1970a) nos seguintes termos: "O fisiólogo designa com o nome de reflexo essa reação regular do organismo animal aos fatores do mundo exterior, reação realizada por meio do segmento inferior do sistema nervoso central"(p. 65-66). Segundo o autor, nesta área são produzidos os denominados reflexos absolutos. Esta espécie de reflexos representa o modo primário de interação do organismo com seu meio, pois corresponde à atividade reflexa inata, cuja via nervosa apresenta-se preparada de antemão para estímulos específicos. O termo "absoluto" refere-se ao caráter permanente do circuito reflexo formado. Esta atividade reflexa inata pode ser estruturalmente simples, como o ato de tossir na presença de um corpo estranho nos órgãos respiratórios, ou complexa, como no caso da diversidade das respostas instintivas (Pavlov, 1934/1970b, p. 106). No entanto, resta compreender como um comportamento pode visar o mundo, adaptar-se e construir mecanismos de interação que não são dados na aparelhagem inata do organismo. A complexidade das demandas ambientais exige do organismo a criação de mecanismos comportamentais temporários, que cumprem a função de ampliar o espectro de respostas em relação aos mecanismos inatos. Este gênero de comportamentos, essencial para a adaptação do animal, é conhecido pelo nome de "reflexo condicionado". Pavlov fornece o seguinte exemplo: se um animal se restringisse a comer apenas aquilo que se apresenta de forma direta, morreria de fome. É preciso que ele procure por comida, o que lhe permite a criação de 
novos padrões comportamentais de sobrevivência a partir de outros conjuntos de estímulos que formarão a base da reflexo condicionado (Pavlov, 1934/1970b).

Em seu texto, "Resposta de um fisiólogo aos psicólogos", Pavlov (1932/1970c) elege três princípios fundamentais para a compreensão científica do fenômeno reflexo. $\mathrm{Na}$ primeira formulação, denominada 'princípio do determinismo', afirma-se que todo fenômeno tem sua origem em uma causa. $\mathrm{O}$ segundo postulado explicita a necessidade de decompor-se a totalidade dos fenômenos observados para, então, analisar suas unidades constitutivas. Este é o "princípio da análise e da síntese”. A terceira normativa do trabalho científico que deve orientar a pesquisa reflexológica se embasa no "princípio da estruturação, isto é, de uma força que desenvolve a sua ação no espaço, ou a associação do movimento à estrutura" (Pavlov, 1932/1970c, p. 209). A definição do reflexo a partir da relação entre "o aparelho receptor, o nervo aferente, a estação central, e o nervo eferente, com seu órgão efetuador" (Pavlov, 1932/1970c, p. 211) conjuga os princípios mencionados, fornecendo um quadro geral da atividade do organismo em termos propriamente mecânicos. A fisiologia do reflexo pode ser descrita como se segue:

Um agente qualquer do mundo exterior ou do mundo interior do organismo atinge um dos aparelhos receptores do sistema nervoso, dando origem a um processo nervoso: o fenômeno de excitação. A excitação conduzida pelas fibras nervosas centrípetas chega até o sistema nervoso central, de onde parte de novo, graças a conexões estabelecidas por outros condutores, para alcançar, finalmente, o órgão efetuador onde é transformada, por sua vez, em um processo específico das células desse órgão. Desta maneira, um agente do mundo exterior entra em determinada conexão com tal ou qual função do organismo, conexão esta que é uma relação de causa a efeito (Pavlov, 1926/1970d, p. 39).

Todos os princípios elencados por Pavlov são identificados nessa caracterização do circuito reflexo. A ação do organismo pode ser desmembrada e descrita a partir dos elementos antecedentes à reação (princípio da análise e da síntese). A coerência funcional do organismo, sua capacidade de alcançar o equilíbrio, é assegurada pela "ordem" da atividade reflexa. Há uma correspondência unívoca entre estímulo, lugar da excitação, condução e reação (princípio do determinismo). Estes elementos fornecem a transformação dos excitantes em respostas locais do organismo ao meio ambiente (princípio da estruturação). Para Pavlov, esta cadeia de acontecimentos constitui o ponto de origem de toda atividade reflexa. Neste modelo, segundo Merleau-Ponty, "a atividade 'normal' de um organismo nada mais é do que o funcionamento deste sistema montado pela natureza; não existem normas verdadeiras, existem apenas efeitos" (1942/1967, p.7). Nesta lógica, a 
teoria do reflexo aparece como um modelo científico viável de explicação do comportamento.

Assim que deixamos de nos fiar nos dados imediatos da consciência e queremos construir uma representação científica do organismo, parece que somos conduzidos à teoria clássica do reflexoou seja, a decompor a excitação e a reação em uma multiplicidade de processos parciais, exteriores uns aos outros tanto no tempo quanto no espaço (Merleau-Ponty, 1942/1967, p.6, p. 7)

De acordo com Merleau-Ponty (1942/1967, p.7), o reflexo consiste na "operação de um agente físico ou químico definido sobre um receptor localmente definido, que provoca, por um trajeto definido, uma resposta definida". O encadeamento destes processos culmina na "adaptação da resposta ao estímulo e a coordenação dos movimentos parciais no gesto total" (Merleau-Ponty, 1942/1967, p.8). Cada etapa da atividade reflexa- recepção, condução e resposta- corresponde, para a teoria reflexológica, à sistemas anatômicos isolados, que não se comunicam, pois expressam por si mesmos as relações interiores e exteriores ao organismo. Por exemplo, os estímulos exteriores ao organismo são considerados como condições do arco reflexo e funcionam segundo o princípio de causa-efeito. Assim, todas as determinações internas ao organismo constituem apenas a arquitetura da condução do estímulo, de modo que a colaboração entre os diferentes setores se efetiva tão somente no sentido de tornar possível a elaboração do estímulo, considerado como causa físico-química de reações orgânicas. A anatomia é, portanto, reduzida às condições topológicas que viabilizam ou facilitam a propagação do estímulo.

O primeiro componente do arco reflexo analisado por Merleau-Ponty é o estímulo. (Merleau-Ponty, 1942/1967). Para Pavlov (1934/1970b), a presença de um agente exterior é condição necessária para a ocorrência do arco reflexo. Nessa medida, a reelaboração do papel do estímulo é de suma importância na crítica ao modelo mecanicista disseminado pela noção de reflexo. Prevalece na teoria do reflexo o conceito físico de estímulo. O físicalismo presente na concepção de estímulo da teoria reflexológica contribui para uma formulação essencialmente "geográfica" do comportamento. Neste ponto, Merleau-Ponty lança mão da distinção conceitual proposta por Koffka (1936) entre meio geográfico e meio comportamental. O meio geográfico designa o ambiente tal como considerado em sua objetividade física, com suas determinações espaço-temporais próprias, independentes da presença do sujeito. O meio comportamental, a seu turno, designa o ambiente em seu modo de aparecimento para o 
organismo, como, portanto, um campo de possibilidades de ação que é prenhe de significações para o sujeito. Koffka (1936, p.29) ilustra esta diferença com o seguinte exemplo. Dois chimpanzés são trazidos, em momentos distintos, a uma jaula, onde há uma caixa no centro e uma banana pendurada no topo. Embora o meio geográfico seja o mesmo para os dois chimpanzés, já que os estímulos físicos são determinados em-si mesmos, a conduta dos animais no ambiente é variável. Enquanto um deles se aproxima da caixa, a avalia e passa a utilizá-la como instrumento para alcançar o alimento, o outro salta repetidas vezes em busca da banana, mas, após algumas tentativas, desiste e sentase na caixa para descansar. Ambos os chimpanzés manipularam o mesmo objeto físico de maneiras diferentes: um utilizando-o como apoio para o salto, o outro como assento. É insuficiente, pondera Koffka (1936), prescrever a diferença no comportamento tão somente a uma distinção individual, precisamente, na medida em que toda conduta já está inserida em um contexto que lhe delimita certas possibilidades de ação. A noção de meio comportamental permite, portanto, compreender a variedade de ações de um organismo sem reduzi-las às suas características individuais e tampouco sem considerá-las como respostas mecânicas aos estímulos físicos. Segundo Koffka (1936, p.31) “o meio comportamental depende de dois conjuntos de condições, uma inerente ao meio geográfico, e outra ao organismo”. Desta forma, no que concerne à teoria reflexológica, os estímulos não representam o meio-ambiente significado pelos valores vitais do animal; ao contrário, o estímulo limitar-se-ia à ação dos excitantes externos sobre o aparelho fisiológico.

Entra em cena a importância do pensamento do médico alemão Kurt Goldstein nas reflexões do jovem filósofo francês. Merleau-Ponty (2006, p.449) reconhece na teoria de Goldstein uma intenção original. Sua fisiologia se constitui como um projeto que caminha na contramão dos postulados da fisiologia clássica, porquanto prescinde de uma concepção prévia do que seria o organismo ou o corpo. Nesta fisiologia tradicional, escreve Merleau-Ponty (2006), a cientificidade de seus postulados depende de uma ontologia materialista, segundo a qual a realidade do organismo resumir-se-ia à realidade da matéria. Todo aspecto valorativo ou significativo do comportamento poderia ser compreendido a partir da combinação de elementos simples da fisiologia humana. A divisão entre fenômenos simples e complexos acompanha as tentativas científicas de estudo da vida. A lógica vigente nesta ontologia cientificista é a de que todo fenômeno designado como "complexo" representa o agrupamento ou uma formação de fenômenos 
de ordem simples. Tal é o ponto de partida endossado pela teoria do reflexo. Goldstein (1934/1983), ao contrário, busca despir-se desta categorização prévia entre simples e complexo, para propor uma delimitação teórica que só tenha sentido a partir do contato com o organismo. Não se trata, assim, de portar um arsenal pronto de conceitos que seriam levados e aplicados no decorrer da pesquisa; o movimento proposto pelo autor é justamente o de suspender toda definição do que conhecemos como "fisiológico", como "organismo" e como "corpo" com o propósito de fornecer-lhes uma roupagem conceitual apenas como termo final da pesquisa. Por isto Merleau-Ponty $(2002, p .450)$ lhe tece o seguinte comentário: "Não se pode saber o que é o organismo antes de entrar em contato com ele; em seguida se definirá o ser fisiológico segundo o que se sabe de fisiologia. Ele procura definir um ser fisiológico em função do fenômeno, tal qual este nos aparece". Desta forma, o problema relação entre estímulo e resposta passa a ser concebido sob outra perspectiva. Se na concepção clássica "a cada parte do estímulo deveria corresponder uma parte da reação" (Merleau-Ponty, 1942/1967, p.10), na físiologia coetânea a Merleau-Ponty concebe-se a atuação do estímulo de acordo com suas propriedades estruturais, como a "distribuição espacial" e o "ritmo" (Merleau-Ponty, 1942/1967,p.8). Em um exemplo utilizado por Goldstein (1934/1983, p.60) e retomado por Merleau-Ponty (1942/1967), um gato descerebrado que regurgita água em seu estado puro, apresenta o reflexo de deglutição perante a adição de algumas gotas de álcool. Porém, a combinação dos elementos da água com os componentes do álcool não possibilita explicar tal reflexo a partir das novas combinações químicas (Goldstein, 1934/1983, p.60). No caso do reflexo rotular, por exemplo, observa-se que a resposta pode variar conforme o estado do organismo no momento do estímulo. Tais observações se inserem em uma ampla gama de experimentos sobre o funcionamento da atividade nervosa, que mostram que o valor do estímulo está diretamente vinculado à própria atividade do organismo, incluindo aí sua situação sensório-motora prévia. Estes experimentos indicam, ademais, que o efeito de um determinado excitante não pode ser compreendido pela soma dos elementos que o compõem (Goldstein, 1934/1983). É o que expressa Merleau-Ponty, retomando a atitude de Goldstein: “É, portanto, no organismo, que nós teremos que buscar o que faz um estímulo complexo ser uma outra coisa que a soma de seus elementos" (1942/1967, p.10)

Além da análise do estímulo, é preciso mostrar ainda como a crítica aos outros elementos do aparelho reflexo revela a insustentabilidade do paradigma reflexológico. Acrescenta-se à hipótese da decomposição do estímulo em elementos parciais as 
hipóteses referentes ao caráter linear da recepção e da condução dos estímulos até a reação. No que concerne à explicação da recepção e da condução do estímulo, a teoria reflexológica supõe vias privadas de condução do estímulo, variáveis conforme o lugar excitado (Pavlov, 1917/1970e, p. 189). No entanto, a seguinte objeção não recebe resposta satisfatória da teoria clássica: como explicar que a estimulação de receptores distintos origina reflexos idênticos e que reflexos diferentes sejam produzidos por estimulações nos mesmos receptores? Segundo Merleau-Ponty, a teoria clássica postula uma multiplicação das vias privadas relacionadas a cada receptor, o que acarreta uma especialização na recepção conforme o tipo de estímulo envolvido. Em outras palavras, a explicação usual para o aparecimento de reflexos variados em caso da excitação dos mesmos receptores embasa-se na especialização e na multiplicação das vias privadas aferentes.

De acordo com Goldstein (1934/1983), não é o lugar da excitação que determina o aparecimento de determinado tipo de reflexo. Alguns reflexos são predominantes em relação aos outros em vista do gênero da excitação em questão. No cachorro, por exemplo, uma variedade de estimulações diferentes desencadeia o reflexo de flexão da pata, como o calor, ou uma picada. Mas o toque ou a simples pressão não demonstram o mesmo efeito (Goldstein, 1934/1983). Frente à terminologia que concebe a recepção como "lugar da excitação", inferindo uma relação pontual com o estímulo, Goldstein (1934/1983) propõe que abordemos um “campo receptivo". Desta forma, o autor deseja mostrar que "a excitabilidade deste campo não é a mesma nem em cada ponto, nem em cada momento, nem em toda circunstância, nem para toda excitação" (Goldstein, 1934/1983, p. 59). A ineficácia das explicações causais no tocante ao estímulo e a insuficiência das explicações localizacionistas, no que diz respeito ao lugar da excitação, conduzem Merleau-Ponty ao questionamento das "vias privadas" de condução do estímulo. Pergunta o filósofo: "Existe um trajeto definido, um processo de condução isolado, quando se vai da excitação à reação? " (Merleau-Ponty, 1942/1967, p.15).

A teoria reflexológica responde afirmativamente e sustenta sua hipótese pela crença na primazia dos estímulos exteroceptivos na formação da atividade reflexa (Pavlov, 1934/1970b). Supõe-se que a existência de vias condutoras preestabelecidas está diretamente relacionada com a atuação de estímulos externos, que incidem nos receptores e são conduzidos nestas vias especializadas até a reação, de forma regular e direta. Conforme dissemos anteriormente, as condições interiores do organismo assumem 
funções de simples encaminhamento, visto que é no estímulo que se deve encontrar a origem mesma da reação. Os aspectos interiores funcionam como estruturas isoladas preestabelecidas, participando do processo apenas a título de paisagem anatômica. Não há participação positiva das condições intra-orgânicas, pois estas não desempenham papéis significativos para o andamento da reação (Merleau-Ponty, 1942/1967). Uma importante consequência do primado da exteroceptividade é a representação do sistema nervoso como uma estrutura em repouso, haja vista que o estado de excitação do funcionamento nervoso decorreria da incidência de estímulos externos. Merleau-Ponty (1942/1967), inspirado na obra de Goldstein, contesta que o funcionamento da atividade reflexa seja mais dependente de estímulos exteroceptivos, ou exteriores, do que das excitações advindas do próprio organismo. De acordo com o autor "todos os reflexos exigem no organismo o concurso de uma multiplicidade de condições exteriores ao arco reflexo que têm, tanto quanto o estímulo, o direito de serem chamadas causas da reação" (Merleau-Ponty, 1942/1967, p.15). Por essa razão, Goldstein (1934/1983) destaca o aspecto ativo e dinâmico da atividade nervosa, contrariando a hipótese do "sistema em repouso". O sistema nervoso, segundo o autor, está em estado permanente de excitação e não depende somente de estímulos exteriores; as circunstâncias internas, os estímulos proprioceptivos, advindos dos músculos esqueléticos, e interoceptivos, oriundos das vísceras, influenciam diretamente nas respostas reflexas.

Neste contexto, torna-se problemática a suposição de vias de condução preestabelecidas, atuando como mecanismos interiores ativados oportunamente. As observações experimentais acerca do campo reflexógeno demonstram que os aspectos anatômicos e funcionais da atividade reflexa não se desenvolvem a partir de interações fortuitas entre sistemas isolados. Depreende-se daí que as condições interiores não se resumem à condução nervosa por estruturas prévias. O fato é que o reflexo pode ser alterado drasticamente em função de aspectos químicos, secretatórios e vegetativos. Conforme os exemplos de Goldstein (1934/1983), retomados por Merleau-Ponty, o efeito do estímulo depende de condições intra-orgânicas que, em alguns casos, acabam por inverter seu efeito original. Hormônios como a pilocarpina e a adrenalina apresentam efeitos variáveis de acordo com o estado do organismo. Em alguns casos, a adrenalina, que usualmente age na estimulação do nervo vago, passa a excitar o nervo simpático. A ação do cálcio de desacelerar o pulso em estado normal apresenta efeitos inversos em situações de insuficiência aórtica (Goldstein, 1934/1983, p.67). A estas dinâmicas 
humorais é preciso acrescentar a influência de fatores posturais, cerebrais e cerebelares. A excitação dos braços de uma estrela-do-mar gera o reflexo de flexão na direção do lado estimulado, caso os braços estejam em posição horizontal. No entanto, se os braços não estiverem uniformes, o movimento de flexão ocorrerá no sentido do ponto mais tensionado. Fatores externos ao ato reflexo, como a fadiga, também podem modificar o caráter da reação. Estes fatos reunidos advogam contra a primazia dos dados exteroceptivos frente à vida orgânica interior, tal como sustenta a fisiologia clássica. É preciso, portanto, reconsiderar o comportamento em vista também das funções internas de colaboração e elaboração da reação, o que significa não somente uma revisão da interpretação dos processos de condução mas, é de suma importância, reavaliar o papel ocupado pelo cérebro.

O papel do cérebro no circuito reflexo

No que diz respeito às intervenções de nível cerebral, Merleau-Ponty (1942/1967) considera que a teoria clássica pressupõe a existência de mecanismos reguladores da atividade reflexa. Tal é a interpretação dada pela teoria reflexológica ao caso do esmagamento dos órgãos internos da rã, conhecido como fenômeno de choque, que altera a atividade de todos os esquemas reflexos (Merleau-Ponty, 1942/1967). Neste exemplo, para a teoria reflexológica, as influências cerebrais aparecem na forma de mecanismos de inibição da atividade reflexa (Merleau-Ponty, 1942/1967). O trabalho do cérebro é definido de modo predominantemente negativo: permitir ou negar certas reações (Merleau-Ponty, 1942/1967). A objeção a este modelo hierárquico da função cerebral parte da observação do comportamento do animal: os mesmos processos inibitórios observados no fenômeno de choque são constatados em casos de seccionamento espinhal, em que não há intervenção cerebral direta. Outro exemplo mostra-se ilustrativo: em condições normais, a excitação da planta dos pés (excitação plantar) é seguida pelo reflexo de flexão dos dedos. Contudo, se o movimento de flexão for substituído por um reflexo de extensão, supor-se-ia que a liberação deste mecanismo reflexo fora causada por lesão nas vias piramidais. Este funcionamento reflexo, conhecido como fenômeno de Babinski, indica que a lesão ocasionou a liberação de um mecanismo reflexo que se encontrava inibido pelas vias piramidais. Subentende-se que, de acordo com a teoria reflexológica, as intervenções cerebrais manifestam-se a partir de processos regulatórios, dispostos como atividades inibitórias ou coordenadoras em segunda instância (Merleau- 
Ponty, 1942/1967). Em ambas as funções, inibitórias ou integrativas, o cérebro permanece um centro hierárquico de controle, elevado a níveis funcionais superiores em relação à atividade reflexa. Nesta composição, os reflexos representam fenômenos de primeira ordem; ao cérebro é delegado o cargo de "governar os automatismos, de associálos, de dissociá-los". (Merleau-Ponty, 1942/1967, p.17). Se a função cerebral se limita a operar dispositivos preestabelecidos, é preciso notar que o aparecimento de determinadas reações reflexas no lugar de outras denota o comprometimento do cérebro em efetuar tais operações. Para a teoria clássica, no fenômeno de Babinski a aparição do reflexo de extensão representa o desordenamento do esquema reflexo habitual, no qual algumas reações automáticas encontram-se inibidas. A doença é expressa como um déficit da estruturação "normal”, o que, em outras palavras, significa dizer que a patologia é um “fenômeno negativo" (Merleau-Ponty, 1942/1967, p.18). Importante sublinhar que, para Pavlov (1934/1970b, p. 116) “é pelo estudo do funcionamento normal que deve começar, e que se começa comumente o estudo de qualquer parte do organismo animal". Ora, como explicar, no entanto, os casos em que a lesão das vias piramidais não é seguida, necessariamente, pelo aparecimento do reflexo de extensão? Segundo a teoria reflexológica, tal fato não é suficiente para negar a presença de mecanismos preestabelecidos, à medida que pode se conjecturar entre a ausência do reflexo e a lesão que supostamente deveria ativar seu funcionamento, um mecanismo de inibição da inibição. O fisiólogo supõe a presença de outra atividade inibitória cujo sentido é explicar a ausência "de um reflexo de extensão arbitrariamente suposto" (Merleau-Ponty, 1942/1967, p.18).

Para Merleau-Ponty, deve-se refutar a hipótese de circuitos preestabelecidos em favor de uma descrição centralizada na experiência, que contemple o caráter originário e significativo da condição patológica para o organismo. Isto significa "aliar a explicação fisiológica à descrição psicológica" (Merleau-Ponty, 1942/1967, p.18). Seja no funcionamento normal, ou na reestruturação pelas vias da doença, o comportamento dos organismos expressa relações irredutíveis aos dados da anatomia. Este aspecto qualitativo da conduta diz respeito aos níveis de organização e integração que são possíveis dentro das condições orgânicas e culturais dos organismos. Por isso, Merleau-Ponty destaca que os comportamentos da criança, do louco ou do primitivo, não podem ser apreendidos com base na conduta do "adulto, sadio, civilizado" (Merleau-Ponty, 1942/1967, p.18). Compreender o fenômeno patológico como reestruturação global do comportamento é 
um passo importante para descrever as intervenções cerebrais no âmbito de valores estruturais conectados com a atividade biológica do organismo. Nesse contexto, qual o novo papel a ser desempenhado pelo cérebro? Sob esta perspectiva positiva, "a intervenção das influências cerebrais teria por efeito reorganizar o comportamento, eleválo a um nível superior de adaptação e de vida, e não apenas associar, dissociar dispositivos preestabelecidos" (Merleau-Ponty, 1942/1967, p.19-20).

O estudo do funcionamento nervoso proposto por Goldstein rejeita explicações negativas (Gurwitsch, 1949/2002, p. 376), que se apoiam em supostos mecanismos de supressão, inibição ou enfraquecimento. Goldstein concebe que o recurso à fenômenos negativos, falhas ou ausências de outros supostos mecanismos, na explicação das patologias acarreta uma multiplicação de hipóteses ad hoc que criam mecanismos inexistentes com o intuito de sanar as falhas explicativas de seus modelos. Em contrapartida, o autor postula que: "todo conhecimento que visa a fatos tem sempre um caráter positivo" (Goldstein, 1934/1983, p.149). Conforme este princípio elencado por Goldstein, as intervenções cerebrais adquirem funções positivas, participando na organização geral da atividade nervosa, sem a necessidade de fazer intervir mecanismos preestabelecidos. A investigação dos processos de condução mostra que o funcionamento do sistema nervoso não pode ser reduzido à suposição de esquemas isolados. Ao funcionamento embasado no automatismo é preciso opor a ideia de que dinâmica nervosa é um processo global e que o comportamento exige a conjunção de condições que não são dadas a priori (Merleau-Ponty, 1942/1967). Para tanto, resta ainda esclarecer a natureza das relações entre substrato nervoso e função psicológica.

O problema das localizações cerebrais.

De acordo com Pavlov (1970f, p. 140), a condição anatômica sine qua non para a existência de reflexos condicionados é a presença de córtex cerebral. Nesse sentido, o córtex seria o lugar de formação dos processos nervosos temporários (Pavlov, 1970f, p.140). A principal função dos hemisférios cerebrais consistiria em incorporar ao aparato reflexo inato "excitantes-sinais condicionados" (Pavlov, 1970g, p.126-127). É a partir desta atividade de integração dos sinais exteriores que o organismo pode ampliar seu escopo de respostas comportamentais. Amparando-se nos estudos de Buytendijk, Plessner, Piéron e, principalmente, Goldstein, Merleau-Ponty (1942/1967, p.66) afirma que organismos que não possuem córtex cerebral podem apresentar reações 
condicionadas. É válido notar, entretanto, que o caráter das respostas difere sistematicamente entre os organismos com o córtex intacto e os organismos lesionados. A presença de reações condicionadas em organismos que não possuem córtex é experimentalmente significativa. De modo geral, ela nos indica que os comportamentos superiores, que exigem do organismo a constituição de um meio comportamental para além dos esquemas reflexos inatos, não se referem a conteúdos anexados ao substrato nervoso.

O problema da localização cerebral fora abordado pela psicopatologia clássica a partir de uma perspectiva que assumia a correspondência entre lesões no substrato nervoso e determinados déficits funcionais (Teixeira, 2005). Assim, a perda de funções como linguagem, comportamento sexual e coordenação motora, por exemplo, era explicada a partir de lesões circunscritas a determinadas áreas do tecido cerebral (Verissimo, 2012). Merleau-Ponty identifica três lacunas principais no programa localizacionista tradicional (1942/1967). O primeiro obstáculo da teoria consiste em se localizar, precisamente, a lesão. De fato, a lesão pode se estender para além das áreas nitidamente observáveis, o que nos conduz a outro problema: o da localização da função. Este ponto relaciona-se diretamente com a questão da delimitação das áreas lesionadas, pois certas funções podem ser alteradas sem que as identifiquemos como funções dos tecidos lesionados. Ademais, lesões focais em áreas distintas do tecido cerebral podem afetar a mesma função. A terceira dificuldade refere-se à definição da patologia e de seu correlato no funcionamento normal. Vejamos, detalhadamente, como Merleau-Ponty explora tais problemas com o propósito de reformular as relações entre comportamento e funcionamento nervoso.

No campo da patologia geral, a metodologia empregada para a compreensão do quadro nosológico prevê uma enumeração das reações conservadas e das reações afetadas ou abolidas (Merleau-Ponty, 1942/1967). Aceita-se a correlação estrita dos sintomas a uma causa fundamental. Observa-se que dos sintomas ao distúrbio há "um encadeamento real de efeitos e de causas" (Merleau-Ponty, 1942/1967, p. 67). Tais princípios são transportados da patologia geral ao terreno da patologia cerebral, de modo que a análise da doença se sustenta na premissa de que "o distúrbio afeta certos fragmentos reais do comportamento" (Merleau-Ponty, 1942/1967, p.67). De acordo com Merleau-Ponty, as explicações destes quadros patológicos eram orientadas, inicialmente, pela hipótese de lesões circunscritas que resultavam na "ausência de certos conteúdos do comportamento" 
(Merleau-Ponty, 1942/1967 p.67). O princípio norteador das teorias localizacionistas consiste em transpor para a dimensão psicológica um modo de análise próprio das ciências naturais. Esta "análise real", tal como praticada por Pavlov, estrutura o mundo fenomenal, ou subjetivo, sob o mundo real, regido por fenômenos físico-químicos.

Por outro lado, na teoria de Goldstein (1934/1983) a investigação do funcionamento nervoso está vinculada a uma teoria do conhecimento biológico. Esta filiação indica que o conhecimento acerca da fisiologia, do corpo e do organismo não pode prescindir de uma análise do comportamento. Para Goldstein (1934/1983), o conhecimento biológico é, justamente, aquele que se detém sobre as atividades que emergem dos processos de adequação do organismo ao seu ambiente. Goldstein não recusa a análise físico-química, mas esta deve ser complementada com uma abordagem interessada na experiência (Merleau-Ponty, 2006, p.455). Essa modificação metodológica possibilita uma reinterpretação dos dados patológicos. Nesse sentido, observa-se, por exemplo, que "as lesões do córtex raramente provocam distúrbios eletivos que afetariam isoladamente certos fragmentos do comportamento" (Merleau-Ponty 1942/1967, p.68). Ao comungar desta nova proposta de análise do funcionamento nervoso, Merleau-Ponty intenciona 'conhecer o 'setor central' do comportamento e entender sua inserção no corpo" (Merleau-Ponty, 1942/1967, p.66). A contraposição às propostas localizacionistas se constitui, portanto, a partir de um redimensionamento teórico e metodológico que culmina em uma "atitude globalista" a respeito dos fenômenos nervosos (Verissimo, 2012, p.79).

O caso das afasias anamnésicas é emblemático para compreendermos esta transição paradigmática entre análise real e análise ideal. Para uma teoria localizacionista, a incapacidade apresentada por pacientes com lesão cortical em nomear certas palavras corresponde a uma perda de estoque léxico, causada por lesão circunscrita. Nesta explicação, o sujeito não consegue utilizar determinadas palavras porque a lesão afetou a área responsável pelo armazenamento de imagens verbais (Merleau-Ponty, 1942/1967). A partir dos trabalhos de Gelb e Goldstein (1925), Merleau-Ponty sublinha o fato de que o paciente consegue empregar determinadas palavras que, até então, parecia não ser mais capaz de utilizar. Por meio de observações clínicas, constatou-se que o uso da palavra não era aleatório, mas que emergia dentro de contextos específicos. Segundo Gelb e Goldstein, o distúrbio original não se refere à perda de determinadas imagens verbais, mas a uma reestruturação de níveis globais de atividade. 
[...] o sujeito não perdeu propriamente as palavras, que continua capaz de empregar em linguagem automática; perdeu o poder de nomear, porque, no ato da denominação, o objeto e a palavra são tomados como representantes de uma categoria, considerados portanto de um certo "ponto de vista" escolhido por aquele que nomeia, e essa "atitude categorial" não é mais possível em um sujeito reduzido à experiência concreta e imediata. O que é inacessível não é pois certo estoque de movimentos, mas certo tipo de ato, certo nivel de ação (Merleau-Ponty, 1942/1967, p.68-69, grifos nossos)

De acordo com este novo gênero de análise as patologias corticais não ocasionariam perda de função, e sim uma reestruturação da atividade total do organismo. Explica Merleau-Ponty: "A transformação patológica acontece no sentido de um comportamento menos diferenciado, menos organizado, mais global, mais amorfo" (1942/1967, pp.69-70). Nesse sentido, as observações clínicas de pacientes com lesão cortical derivadas dos trabalhos de Head, Woerkom, Goldstein e Gelb atestam a possibilidade de uma definição estrutural do fenômeno patológico. Para estes autores a lesão cortical causa uma modificação fundamental no comportamento. A nomenclatura utilizada por Merleau-Ponty para indicar este distúrbio elementar é emprestada de Goldstein, e refere-se à experiência patológica como uma perturbação da atitude categorial, ou da função simbólica (Goldstein, 1934/1983).

A perturbação da atitude categorial afeta a "faculdade de adotar a perspectiva do possível” (Goldstein, 1934/1983, p.28). Sobressai-se das reflexões de Goldstein (1934/1983) uma caracterização do distúrbio enquanto incapacidade de aderir ou criar situações abstratas. Com efeito, os comportamentos de pacientes com lesões corticais, analisados pelo psiquiatra alemão, apresentavam uma ambigüidade notável. Se, por um lado, suas condutas pareciam desordenadas frente a problemas que exigiam soluções de caráter virtual, imaginário ou fictício, por outro, apresentavam comportamentos precisos e adequados em situações concretas, com vínculos reais no presente ou na história do paciente. De modo geral, portanto, o distúrbio fundamental elencado pelos autores evidencia uma reestruturação do campo comportamental, que passa a ser definido pela incapacidade do paciente em se dirigir ao "possível” das situações.

O caso Schneider, analisado por Gelb e Goldstein, representa um exemplo clássico de perda da função simbólica. O paciente em questão fora atingido por estilhaços de ôbus durante a guerra. Diversas categorias de seu comportamento foram afetadas, tais como a percepção visual, a memória e a linguagem. Pelo viés de uma interpretação localizacionista, poder-se-ia afirmar que a diversidade dos distúrbios se origina, 
justamente, de uma multiplicidade de áreas lesionadas (Merleau-Ponty, 1942/1967). Assim, cada área atingida representaria uma função correspondente prejudicada. No entanto, conforme pontua Merleau-Ponty (1942/1967), lesões múltiplas deveriam acarretar, minimamente, alterações severas no comportamento sensório-motor. A observação revela, ao contrário, que a conservação da integridade sensório-motora corresponde à "aparência normal do comportamento" (Merleau-Ponty, 1942/1967). Ademais, o paciente ainda apresenta comportamentos que possuem uma ligação estreita com as demandas ambientais presentes. Não obstante, ele demonstra dificuldades em realizar movimentos que exijam uma relação potencial, ou virtual com certos problemas. Quando picado por um mosquito, Schneider não hesita em levar a mão ao ponto picado. Em contrapartida, ao receber uma ordem para que faça um quadrado no ar, ele traça aleatoriamente repetidos esboços até que enfim o movimento requisitado "apareça" (Merleau-Ponty, 1945). Para Schneider, torna-se problemática a conciliação entre os atos de mostrar (Zeigen) com as ações que visam pegar (Greifen) alguma coisa. Ao ser requisitado para que mostre seu nariz só lhe é possibilitada tal atividade se ele puder tocálo. (Merleau-Ponty, 1945). O ponto de vista adotado por Merleau-Ponty como parâmetro descritivo da experiência patológica tem em vista "a elaboração de uma representação do funcionamento nervoso adequada à ambigüidade do lugar na substância nervosa" (Verissimo, 2012 p.83). A ambiguidade da localização se refere à ideia de que o lugar no substrato nervoso conserva certa relação com determinada função, mas que esta relação também se envolve no conjunto da atividade nervosa. A lesão não afeta conteúdos isolados, mas opera pela via de uma "desintegração sistemática", na medida em que há uma reorganização da totalidade do sistema e não apenas do lugar afetado (Goldstein, 1934/1983, p.29). Por essa razão, o caso Schneider deve ser considerado como um “distúrbio de estrutura determinado por lesão circunscrita" (Merleau-Ponty, 1942/1967, p.71).

Este processo de desdiferenciação do comportamento ocasionado por lesão, fora observado em experimentos com animais. Merleau-Ponty (1942/1967) retoma os estudos de Lashley, que relatam casos de ratos com lesões nos setores centrais do córtex apresentando dificuldades análogas aos pacientes de Goldstein. Os experimentos revelam que o animal não perdeu a habilidade de executar movimentos essenciais- como andar, comer, pular. É notável, contudo, que a lesão alterou a estrutura geral do movimento, tornando-o desajeitado, rígido e lento (Merleau-Ponty, 1942/1967, p.73). Colocado para 
caminhar numa prancha estreita, o animal não consegue ajustar seus movimentos em relação ao espaço ofertado. Disto resulta que ele frequentemente cai, ou escorrega. Em experimentos envolvendo a transferência de hábitos em ratos, a situação demandava aos animais percorrer o labirinto em busca do objetivo, que não era mantido muito tempo no mesmo lugar. Os ratos operados mostraram dificuldades em alterar os caminhos escolhidos nas primeiras vezes. Ratos normais, ao serem posicionados em labirintos em formato de $\mathrm{T}$, tendem a escolher o caminho que os levará ao ninho e, rapidamente, mudam seu trajeto se o ninho não estiver no lugar esperado. Em ratos operados, por outro lado, os hábitos ligam-se "às propriedades particulares concretas", dificultando a mudança nas ações habituais (Merleau-Ponty, 1942/1967). Ainda assim, é importante perguntarmo-nos como os ratos não operados conseguem, tão facilmente, desvencilhar-se dos elementos próprios à situação e buscar novas soluções? De acordo com Merleau-Ponty, a dependência em relação à estrutura atual da situação no caso dos ratos operados é diferente nos animais sem lesões, pois estes se adaptam a "uma certa estrutura típica" (1942/1967, p.74). Poderíamos resumir essas observações afirmando que o rato operado, tal como o homem com lesão cerebral, deixa de regular seu comportamento a partir daquilo que existe de essencial numa situação. Com efeito, “o distúrbio geral das funções consiste numa percepção reduzida dos conjuntos (Gestalten) e numa diferenciação reduzida das ações" (Merleau-Ponty, 1942/1967, p.74).

Todas as observações anteriores conduzem Merleau-Ponty à rejeição da ideia de que os comportamentos superiores estejam armazenados no tecido cerebral. Nesse sentido, Merleau-Ponty considera que "uma lesão na região central do córtex produz os efeitos observados não quando destrói algumas células, algumas conexões, mas quando compromete certo tipo de funcionamento ou certo nível de conduta" (Merleau-Ponty 1942/1967, p.80). No entanto, a crítica à noção de localização clássica levada a cabo por uma atitude globalista não resultaria em uma concepção indiferenciada de atividade nervosa, onde tudo dependeria de tudo? Este é um ponto que demanda cuidado, pois as críticas tecidas à teoria localizacionista não visam dirimir completamente as relações entre substrato e função. Desta forma, "os fatos que obrigam a admitir uma especialização das regiões cerebrais não suprimem a relação dessas regiões com o conjunto no funcionamento" (Merleau-Ponty, 1942/1967, p.77).

Por exemplo, em casos de lesão na área occipital, o que determina a função a ser alterada (visão de cores, visão de formas, visão de luzes) não é o ferimento de um locus 
específico que conteria uma função correspondente. Segundo a proposta de MerleauPonty (1942/1967), é possível compreender a dinâmica nervosa sem a necessidade de sobrepor a cada área do córtex um centro funcionalmente isolado. Isto significa, por exemplo, que no déficit visual ocasionado por lesão occipital observa-se uma desintegração ordenada da função, que atinge, primeiramente, as funções mais frágeis. Goldstein (1934/1983, p.31) ressalta que o processo de desintegração funcional é hierárquico, mas que esta hierarquia não é composta por uma justaposição de comportamentos ou funções. Neste modelo de funcionamento integrado do substrato nervoso, contrário à clássica ideia da repartição em áreas sub-especializadas, a desintegração, ou a conservação de certas funções está diretamente vinculada aos parâmetros impostos pela normatividade vital dos organismos. A readaptação da atividade nervosa frente a qualquer perturbação se constitui como um processo de manutenção das funções que possuem importância vital para o organismo (Goldstein1934/1983, p.31). De acordo com Goldstein (1934/1983, p.43), "quando um domínio funcional é alterado, as operações mais importantes são preservadas por mais tempo, e são restabelecidas da forma mais perfeita"

Merleau-Ponty (1942/1967) enfatiza que os fenômenos de readaptação nervosa se orientam para o equilíbrio funcional da atividade. $\mathrm{O}$ autor destaca como um caso emblemático de equilíbrio funcional a experiência patológica da hemiopia. Em linhas gerais, a hemiopia caracteriza-se como um distúrbio visual causado por lesão total na calcarina- área dos hemisférios em que se localizam terminações de vias ópticas. Exames que determinam a amplitude do campo visual revelam que os pacientes hemiópticos apresentam sensibilidade à luz em apenas metades de suas retinas (Merleau-Ponty, 1942/1967). Consequentemente, a destruição da calcarina deveria acarretar uma redução do campo visual pela metade. No entanto, os pacientes relatam que enxergam mal, mas não mencionam nenhuma espécie de redução brusca do campo percebido (Goldstein, 1934/1983). Além disso, encontra-se conservada a capacidade de explorar os lados de um ponto central do campo visual, habilidade esta que é fundamental na experiência normal.

O sentido biológico dos comportamentos

Eis o momento de delimitarmos os resultados das análises empreendidas anteriormente, relacionando-as com a noção de forma. Em uma organização gestáltica "cada momento é determinado pelo conjunto dos outros e seu valor respectivo depende 
de um estado de equilíbrio total" (Merleau-Ponty, 1942/1967, p. 101). Os processos de reorganização da atividade total do organismo demonstram que a ruptura do funcionamento gestáltico ocasionada por lesão não se configura nos moldes de uma subtração de determinados conteúdos enraizados no substrato tecido cerebral. A lesão afeta níveis de expressão, correlacionados com a capacidade de orientarmo-nos para além dos aspectos concretos da situação.

A partir deste quadro geral, informado pela noção de estrutura, Merleau-Ponty leva a cabo uma definição da atividade vivente em termos de figura-fundo. $O$ funcionamento normal do sistema é garantido pela dialética entre processos de primeiro plano, e processos de segundo plano (Goldstein, 1934/1983). É importante frisar que, se para Pavlov "O conjunto dos reflexos constitui o fundamento principal da atividade nervosa do homem e do animal." (Pavlov, 1970d, p. 43), por outro lado, Goldstein defende "esta configuração de excitação, a relação figura-fundo, como a forma básica do funcionamento nervoso" (Goldstein, 1934/1983, p.93). A dimensão figural da atividade nervosa consiste nos processos que se destacam em relação às tarefas atuais do organismo. A percepção visual, por exemplo, necessita que determinadas funções assumam o caráter de figura, como os processos envolvendo os centros óticos, enquanto a linguagem, por sua vez, requer dimensões figurais ligadas a outras prioridades. A descrição do funcionamento nervoso na perspectiva de processos figura-fundo altera drasticamente os papéis assumidos pelas funções e pelo substrato nervoso. Nas palavras de Merleau-Ponty:

\begin{abstract}
A função tem pois uma realidade positiva e própria, não é uma simples conseqüência da existência dos órgãos ou do substrato. O processo de excitação forma uma unidade indecomponível e não é feito da soma dos processos locais. A cor ou a posição que serão efetivamente percebidas por causa dessas excitações retinianas não dependem apenas das propriedades destas últimas, mas das leis próprias do funcionamento nervoso. Não são os estímulos que fazem as reações ou que determinam o conteúdo da percepção. Não é o mundo real que faz o mundo percebido. (MerleauPonty, 1942/1967, p.97, grifos nossos)
\end{abstract}

O estudo das relações entre comportamento e funcionamento nervoso revela que a atividade orgânica é uma totalidade orientada por significações vitais (Marangoni \& Verissimo, 2018). N'A Estrutura do Comportamento, desde as considerações iniciais sobre o problema das localizações, Merleau-Ponty preocupa-se com a questão da ambivalência do espaço corporal (Verissimo, 2012). A noção de estrutura possibilita, nesse sentido, uma interpretação do funcionamento nervoso calcada na dimensão 
biológica da atividade. A inserção do paradigma da forma nos debates acerca do funcionamento nervoso tem implicações notórias no que concerne à definição da ação vivente. Precavendo-se por uma atitude globalista torna-se possível descrever a aquisição de comportamentos sem a necessidade de se recorrer à noção de reflexo.

Uma questão importante permanece: como um organismo pode conjugar a ação dos agentes externos e a sua situação orgânica, a fim de comportar-se com mais eficiência e objetividade perante seu meio? Segundo Goldstein (1934/1983), mesmo nos comportamentos aparentemente automáticos, desde a mão que alcança o ponto picado de forma rápida e eficaz, até a atividade dos organismos que se encontram em situações de risco vital, o comportamento reflexo aparece como uma espécie de "fenômeno orientado". Nestes moldes, é inevitável questionar a antiga lógica do caráter longitudinal dos reflexos: "Pode-se imaginar, no ponto coçado, tantos circuitos preestabelecidos quantas posições iniciais possíveis para a mão existem? Também não se entenderia como o influxo escolhe, entre as vias abertas, justamente aquela que provocará o movimento conveniente na situação considerada" (Merleau-Ponty. 1942/1967, p.28)

De acordo com Merleau-Ponty (1942/1967), a questão da adaptação da resposta frente às mudanças impostas pelo meio é visível nos casos em que o organismo sofre amputações ou lesões graves. Nestas ocasiões, vê-se emergir o fenômeno de suplência, que consiste em um processo de "reorganização do funcionamento" (Merleau-Ponty, 1942/1967, p.40), pelo qual as funções de órgãos debilitados são compensadas pela atividade integralizada entre outros setores. Ante a teoria clássica que postula a ativação de mecanismos prontos a funcionar, é preciso objetar que a atuação dos fenômenos de suplência "se produz de uma maneira característica apenas se um interesse vital está em jogo, e não quando se trata de um ato encomendado" (Merleau-Ponty, 1942/1967, p.40). Merleau-Ponty analisa o exemplo do comportamento de um escarabeídeo, espécie de besouro, após a amputação de suas falanges. A extirpação de seus membros não é suficiente para que o animal deixe de se locomover, fenômeno este que pode ser interpretado, em um primeiro momento, como o desencadeamento de processos automáticos de reorganização. Contudo, pondera Merleau-Ponty (1942/1967), a geografia do terreno participa de forma crucial na função: mantêm-se a similitude com o caminhar normal em solos irregulares, nos quais há a possibilidade de variar os pontos de apoio, mas o mesmo não se sucede se o terreno for liso. Este exemplo ilustra a possibilidade de se pensar a adaptação a partir de uma normatividade interna ao 
organismo que dialoga com o espaço geográfico. Em outros casos, que não envolvem propriamente amputação, e sim imobilização, os fenômenos de suplência são substituídos pelo esforço total do organismo em liberar-se, o que, eventualmente, desencadeia um “comportamento desordenado" (Merleau-Ponty, 1942/1967). Para Goldstein (1934/1983), é necessário contrapor-se à ideia do organismo como um amontoado de instintos prontos a funcionar. A hipótese de uma variedade de instintos diferentes ordenando setores isolados da vida do organismo cede lugar à ideia de que todas as modalidades de interação do organismo podem ser descritas a partir de uma atividade mais primordial, uma única pulsão: “a atualização de si” (Goldstein 1934/1983, p.169). Tal conceito refere-se ao movimento inerente à vida orgânica de busca de realização e desenvolvimento de suas capacidades, que não se esgota na preservação de si, mas que a todo momento se renova na dialética entre organismo e seu meio. Segundo Goldstein (1934/1983), a conservação-de-si não diz respeito apenas à manutenção da existência, visto que o organismo se engaja no mundo significando-lhe a partir de seus potenciais de ação. Com efeito, Goldstein (1934/1983) considera que a restrição a estados de conservação corporal caracteriza as ações de um organismo em condição patológica, já que nestes casos haveria uma redução considerável da capacidade do organismo em “atualizar-se". É, portanto, com a imobilização da busca pela atualização de suas capacidades de ação que desponta o processo de regressão à conservação da existência, descrita como "um signo de vida anormal, de vida em declínio" (Goldstein, 1934/1983, p.170).

Os experimentos reflexos, tal como vemos em Pavlov, têm como objetivo fornecer leis de funcionamento do organismo, embasadas, sobretudo, em hipóteses acerca da atividade nervosa. A objetividade de sua teoria ampara-se no preceito de que " é o estudo fisiológico do funcionamento cerebral que deve servir de base ao estudo subjetivo do homem" (Merleau-Ponty, 2006, p.456). As inferências produzidas pela teoria clássica generalizam a atividade do organismo a partir de comportamentos observados em contextos controlados. De acordo com Merleau-Ponty (1942/1967), tais tipos de inferência descontextualizam a realidade biológica em prol de uma fundamentação anatômica que se embasa na relação do organismo com estímulos artificiais. Assim como nos estados patológicos, o comportamento do organismo em condições experimentais torna-se desordenado, principalmente em vista da artificialidade dos estímulos, que são destituídos de um valor vital para o animal. Segundo Merleau-Ponty (1942/1967, p. 45), 
o isolamento artificial dos estímulos coloca os organismos face a uma "situação antropomórfica". A significação funcional do comportamento animal como relação dialética com seu meio natural perde-se no contexto do laboratório dado o caráter pontual das estimulações às quais o organismo deve reagir.

É preciso afirmar, portanto, que o reflexo não representa a atividade normal do organismo, ele expressa, ao contrário, "a reação que se obtém de um organismo quando o obrigamos a trabalhar, por assim dizer, por peças isoladas, a responder, não a situações complexas, mas a estímulos isolados" (Merleau-Ponty, 1942/1967, p.45). Segundo Goldstein, o reflexo pode ser descrito "como uma operação do organismo total alterado pela doença, ou pela intervenção experimental" (Goldstein, 1934/1983, p. 134). Para estes autores, o reflexo expressa um tipo de compromisso particular entre organismo e meio, pelo qual os organismos são obrigados a ofertar respostas isoladas, destituídas do valor vital que envolve as condutas em seus contextos. A capacidade de responder a estímulos isolados está na origem da dinâmica nervosa apenas na patologia e nas situações experimentais (Goldstein, 1934/1983). O reflexo não consiste no mecanismo fundamental de interação das formas inferiores de vida: o nível de adaptação do organismo é inversamente proporcional ao uso de atividades reflexas (Goldstein, 1934/1983). Quanto mais o organismo encontra-se "centrado" e "adaptado" ao seu meio, menor será a frequência de respostas reflexas. Em níveis superiores da escala zoológica, as ações devem adaptar-se a ambientes potencialmente mais complexos. A presença de reflexos, ou fenômenos semelhantes, atesta uma capacidade comportamental complexa de “produzir no próprio organismo isolamentos artificiais" (Goldstein, 1934/1983, p.146). Tal capacidade, sugere o autor, talvez pertença somente aos seres-humanos. (Goldstein, 1934/1983). É o caso, por exemplo, do reflexo pupilar, observado mediante a iluminação dos olhos. Neste procedimento, o sujeito examinado "abandona" a função do olhar, e “empresta' o olho ao examinador (Goldstein, 1934/1983). Apesar de constatar-se uma variação normal do diâmetro da pupila na atividade habitual do organismo, em relação ao olhar artificial que se deve emprestar aos exames médicos, e sob a mesma intensidade luminosa, a contração produzida é diferente caso a visão direcione-se a um objeto de interesse (Goldstein, 1934/1983, p.146).

A definição objetiva do comportamento, apresentada por Pavlov, orbita em torno da noção de reflexo e estabelece o privilégio dos fatos fisiológicos sob os dados comportamentais. De acordo com Merleau-Ponty (1942/1967), esta posição possui 
fragilidades teóricas, dado que a teoria do reflexo é apresentada como uma complexão de suposições ou hipóteses acerca dos eventos cerebrais que acarretariam, de modo causal, o acionamento dos esquemas motores. Ao invés de caracterizar negativamente os fenômenos nervosos, pressupondo a existência de entidades não-verificáveis, a teoria de Goldstein erige sua metodologia com base em uma concepção estrutural do organismo, na qual a atividade nervosa está em sintonia com o valor biológico das ações. Essa mudança nos fundamentos envolve a crítica à ideia de que a topografia fisiológica- o circuito reflexo- seja por si só determinante da atividade biológica. Se na fisiologia clássica a divisão dos fenômenos em núcleos isolados guiava a compreensão da atividade nervosa, por outro lado, a fisiologia contemporânea a Merleau-Ponty busca ater-se aos fenômenos por meio da descrição genuína de seu aparecer, sem recorrer a hipóteses auxiliares. Nessa medida, o método fisiológico empregado por Pavlov consiste, nas palavras de Merleau-Ponty (1942/1967, p.89), em uma "fisiologia imaginária". O ponto culminante dos exames precedentes é a demonstração de que o isolamento artificial constitui a base dos experimentos de Pavlov. A descrição do funcionamento nervoso neste modelo obedece à lógica das condições artificiais do laboratório. Segundo Merleau-Ponty (1942/1967, p.18), a teoria do reflexo deveria "tornar inteligível o próprio fato", mas termina por "mascarar um desacordo visível entre a teoria e a experiência". Para Goldstein (1934/1983), os critérios de decomposição e análise elementar, pilares das ciências naturais, revelam que a experiência do isolamento constitui o fundamento do próprio conhecimento científico. É, nesse sentido, que as considerações tecidas por Merleau-Ponty fornecem elementos críticos que não se restringem ao campo metodológico, mas que possibilitam compreender como uma determinada concepção de ser, no caso a ontologia cientificista, gera prejuízos no modo como pensamos o comportamento, o organismo e o mundo.

\section{Considerações finais}

A crítica à fisiologia clássica cumpre um papel central na redefinição da noção de organismo e de comportamento na primeira obra de Merleau-Ponty. Defendemos a hipótese de que o edifício da representação científica do comportamento, retratada pela teoria de Pavlov, alicerça-se em uma concepção linear de estímulo e em uma definição localizacionista do funcionamento nervoso. Ambas ideias são pilares sob os quais uma 
teoria mecanicista e determinista do comportamento se erige. A obra de Goldstein fornece à Merleau-Ponty a possibilidade de pensar a percepção e o comportamento como relações dialéticas estabelecidas entre o organismo e seu meio. O privilégio de uma análise centrada nas partes, na fisiologia clássica, cede lugar à uma fisiologia aliada à experiência direta, pela qual o organismo será compreendido como uma totalidade ativa, em que as funções das partes já influenciam e são influenciadas pela dinâmica de todo o comportamento. Compartilhamos da interpretação fornecida por Bimbenet (2004), segundo a qual haveria uma nuance conceitual entre duas ideias aparentemente sinônimas na obra de Merleau-Ponty: a forma e estrutura. Para o autor, Merleau-Ponty repousa a "totalidade perceptiva sob a significação funcional" (Bimbenet, 2004, p.54), o que significa que a teoria da percepção presente na Psicologia da Gestalt é incorporada sob as bases de uma filosofia do vivente, proporcionada pelo estruturalismo de Goldstein. $\mathrm{Na}$ perspectiva de Pintos (2008), outra importante comentadora de Merleau-Ponty, cujo foco de suas publicações tem sido, justamente, a gênese inicial de seu pensamento, Goldstein aparece como uma figura definitivamente central para a compreensão da teoria de Merleau-Ponty. Neste contexto, nosso trabalho visa complementar esta tradição exegética, que confere à Goldstein um lugar importante na obra de Merleau-Ponty, a partir da reconstrução dos argumentos que permitiram à Merleau-Ponty efetuar a crítica à fisiologia clássica. Ademais, isto nos permitiu o movimento de abordar diretamente a obra de Pavlov, buscando correlacioná-la com o conteúdo apresentado n'A Estrutura do Comportamento.

Fomento: Fundação de Amparo à Pesquisa do Estado de São Paulo (processo no 2017/15348-3)

\section{Referências}

Barbaras, R. (2001). Merleau-Ponty et la psychologie de la Forme. Les Études philosophiques, $59,151-163$

Bimbenet, E. (2004) Nature et Humanité : le problème anthropologique dans l'oeuvre de Merleau-Ponty. Paris : Vrin

Ellis, R. (2006). Phenomenology-Friendly Neuroscience: The return to Merleau-Ponty as Psychologist. Human Studies, 29, 33-55.

Gelb, A., \& Goldstein, K. (1925). Psychologische Analysen hirnpathologischer Fälle. Psychologische Forschung, 6(1), 187-199. 
Goldstein, K. (1983). La Sructure de l'organisme. ( E. Buckhartdt \& J. Kuntz. Trad.) Paris: Gallimard.( Obra original publicada em 1934)

Gurwitsch, A. (2002) La science biologique d'après M.K. Goldstein. In Esquisse de la Phénoménologie Constitutive. Paris : Vrin. (Obra original publicada em 1949).

Koffka, K (1936) Principles of Gestalt Psychology. London: Kegan Paul, Trench, Trubner \& Co.. Ltd.

Laurenti, C. (2016). Metodologia de pesquisa conceitual em Psicologia In: Laurenti, C; Lopes, C.E.; Araújo, S. (orgs): Pesquisa teórica em Psicologia: aspectos filosóficos e metodológicos. São Paulo: Hogrefe,41-69.

Marangoni, P, \& Verissimo, D. (2018). Intencionalidade e comportamento: a percepção vivente em Merleau-Ponty. Revista da Abordagem Gestáltica, 24(1), 75-83.

Merleau-Ponty, M (1989) A natureza da percepção. In: O primado da percepção e suas consequências filosóficas. (C. M. César, Trad.) Campinas: Papirus. (Obra original publicada em 1971)

Merleau-Ponty, M. (1967) La structure du Comportement. Paris: Presses Universitaires de France (Obra original publicada em 1942)

Merleau-Ponty, M. (2006) Fenomenologia da Percepção (C.A.R de Moura Trad.) São Paulo: Martins Fontes. (Obra original publicada em 1945)

Merleau-Ponty, M (2006) Ciências Humanas e Fenomenologia . In Psicologia e Pedagogia da criança: Curso da Sorbonne 1949-1952 (Benedetti I. Trad.) São Paulo: Martins Fontes

Pavlov, I (1970a). O cérebro e as ciências naturais. In: Pavlov: Obras Escolhidas. (U. Uflaker \& E. Andreoli, Trads.) São Paulo: Hemus, 65-77. (Obra original publicada em 1909)

Pavlov, I (1970b). O Reflexo Condicionado. In: Pavlov: Obras Escolhidas. (U. Uflaker \& E. Andreoli, Trads.) São Paulo: Hemus. 103-124. (Obra original publicada em 1934)

Pavlov, I (1970c). Resposta de um fisiólogo aos psicólogos. In: Pavlov: Obras Escolhidas. (U. Uflaker \& E. Andreoli, Trads.) São Paulo: Hemus, 199-232. (Obra original publicada em 1932)

Pavlov, I (1970d). O trabalho dos grandes hemisférios cerebrais. In: Pavlov: Obras Escolhidas. (U. Uflaker \& E. Andreoli, Trads.) São Paulo: Hemus, 33-47. (Obra original publicada em 1926)

Pavlov, I (1970e). A Fisiologia e a Psicologia no estudo da atividade nervosa superior dos animais. In: Pavlov: Obras Escolhidas. (U. Uflaker \& E. Andreoli, Trads.) São Paulo: Hemus, 183-198. (Obra original publicada em 1917)

Pavlov, I, (1970f) Resultados de experimentos sobre a extirpação de diversas regiões corticais pelo método dos reflexos condicionados. In: Pavlov: Obras Escolhidas(U. Uflaker \& E. Andreoli, Trads.). São Paulo: Hemus. 139-153. 
Pavlov, I. (1970g) Fisiologia da atividade nervosa superior. In: Pavlov: Obras Escolhidas.

Tradução Ugolino Uflaker; Elena Andreoli. São Paulo: Hemus, 125-138.

Pintos, M. (2008) El neuropsiquiatra Kurt Goldstein em la génesis del pensamento fenomenológico de Merleau-Ponty. Investigaciones Fenomenológicas, 1, 109-141.

Smith, B. Merleau-Ponty and the generation of animals (2007). PhaenEx, 2 (2), 170-215.

Teixeira, J. (2005) Filosofia da mente: neurociência, cognição e comportamento. São Carlos: Editora Claraluz.

Thompson, E. (2007) Mind in Life: biology, phenomenology and the sciences of mind. Cambridge, Massachusetts: Harvard University Press, 2007.

Varela, F; Thompson, E; Rosch, E. (1991) The Embodied Mind: Cognitive Science and Human Experience. New York: MIT Press.

Verissimo, D. (2012) A Primazia do corpo próprio: Posição e crítica da função simbólica nos primeiros trabalhos de Merleau-Ponty. São Paulo: Unesp. 